\title{
Optical method for the absolute measurement of small lengths
}

\section{Macé de Lépinay}

To cite this article: M. Macé de Lépinay (1885) Optical method for the absolute measurement of small lengths, Philosophical Magazine Series 5, 20:122, 79-80, DOI: $10.1080 / 14786448508627730$

To link to this article: http://dx.doi.org/10.1080/14786448508627730

册 Published online: 29 Apr 2009.

Submit your article to this journal

Џ Article views: 2

Q View related articles $\square$ 
holds for iron from $0^{\circ}$ to $-92^{\circ}$, with $\alpha=0.0049$, but it does not hold for platinum. The value of $\alpha$ deduced from the formula (2), which near $0^{\circ}$ would be about 0.0030 , increases as the temperature sinks, and becomes 0.00342 for a lower limit equal to $-94^{\circ .57}$; hence platinum approaches the other pure metals as the temperature sinks.

In conclusion, our experiments prove that the electrical resistance of most metals decreases regularly when the temperature sinks from $0^{\circ}$ to $-123^{\circ}$, and that the coefficient of variation is appreciably the same for all. It seems probable that this resistance would become extremely small, and therefore the conductivity very great, at temperatures below $-200^{\circ}$, although our experiments do not enable us to form any precise idea of what would take place in those conditions.-Comptes Rendus, May 11, 1885.

\section{OPTICAL METHOD FOR THE ABSOLUTE MEASUREMENT OF SMALL} LENGTHS. BY M. MACÉ DE LÉPINAY.

M. Mouton* gave an ingenious method for measuring, in wavelengths, the thickneas of a quartz plate cut parallel to the axis, which depends on a determination, by means of a known grating, of the wave-lengths of Fizeau and Foucault's dark bands. Uilfortunately it depends on our really very imperfect knowledge of the values $n^{\prime}-n$ of the two indices of quartz for different radiations, and cannot therefore give numbers which are exact to within $\frac{1}{1000 .}$ On the other hand, the corrections for temperature are considerable : $\frac{1}{10000}$ for a degree Centigrade.

I. The method which I have used, which is analogous in principle to the preceding, depends on an observation of 'Talbot's bands $\uparrow$, obtained by intercepting half the pencil of sunlight which falls on a known grating by a quartz plate with true parallel faces. The spectra deflected on the side of the plate are then channelled with lines, in general extremely fine, but which for that very reason tend to a point as exact as that of the spectrum. By using the third spectrum of a grating of $\frac{1}{500}$ millim., I have been able to apply the method directly to a quartz plate parallel to the axis, about 4 millim. in thickness. It is known that the wave-lengths corresponding to the centre of each of these dark bands are related to the thickness of the plate $e$, and the index $n$, by the formula

$$
2 \frac{n-1}{\lambda} e=p
$$

$p$ being an even whole number, which measures the number of the order of the fringe observed, and which increases by two units in passing from one band to the other, counting from red to violet. We thus obtain as many values very near the desired thickness as are observed, and the mean is taken.

In the preceding formula the index is directly given to within

* Journal de Physique, vol. viii. p. 393 (1879).

$\dagger$ Journal de Physique, vol. i. p. 177 (1872). 
one or two units near the fifth decimal place, by either of the formulæ*

$$
\begin{aligned}
& (n-1.52642)\left(\lambda-1.5182 \times 10^{-5}\right)=7.7733 \times 10^{-7}, \\
& \left(n^{\prime}-1.53519\right)\left(\lambda-1.5504 \times 10^{-5}\right)=7.8594 \times 10^{-7} ;
\end{aligned}
$$

calculated by taking the mean of the very concordant measurements of the indices made by Rudberg, Mascart, and Van der Willigen, taking for the wave-lengths the means of the measurements made by Mascart, Ditscheiner, Van der Willigen, and Angström; the latter numbers were transformed so as to correspond to the wavelength $\lambda_{\mathbf{D}_{2}}=5.888 \times 10^{-5}$ adopted by $M$. Mascart. The constant of the grating having been determined each time so as to satisfy this condition, we see that the thicknesses are provisionally measured as a function of what M. Mouton calls Praunhofer's millimetre.

II. A double correction for temperature must be introduced in the thicknesses thus calculated. If by $\theta$ we denote the temperature to which correspond the indices given by the formula above, by $t$ that at which the measurements were made, the thickness $e_{0}$, at $0^{\circ}$ of the plate, should be calculated by the formula

$$
2 e_{0}(1+k t)\left(n+\nu^{\prime} \theta-\nu t-1\right)=p \lambda ;
$$

$k, \nu$, and $\nu^{\prime}$ being coefficients determined, the first by $\mathbf{M}$. Benoit, the two others by M. Dufett. It is more simple and just as exact to correct the thickness $e_{0}$, originally calculated by one or other of the two simplified formulæ,

or

$$
\begin{aligned}
& e_{0}=0.999741(1-0.0000019 t) e \text { ordinary rays, } \\
& e_{0}=0.999709(1-0.0000001 t) e \text { extraordinary rays. }
\end{aligned}
$$

These two formulæ; apply to the case in which the plate is cut parallel to the axis.

III. I applied this method to two quartz plates cut parallel to the axis made by Hoffmann. The thinnest of them measured directly (123 bands observed, ordinary rays) gave

$$
e_{0}=0.402958 \mathrm{~cm} . \pm 0 \cdot 000001 \text {. }
$$

On the other hand, we measured the difference in thickness of two plates (123 bands observed, extraordinary rays). From this was deduced for the thickest plate,

$$
e_{0}=0.602316 \mathrm{~cm} . \pm 0.000003 \text {. }
$$

IV. We may add that this method may lead to a new determination of the absolute value of the wave-length of the ray $D_{2}$. The thickness of the second plate, which M. Benoit kindly measured with the apparatus of the Bureau international des Poids et Mesures, was found equal to 0.60236 to within $1^{\mu}$ or $2^{\mu}$. From this we get for the wave-length of the line $\mathrm{D}_{2}$, the number

$$
\lambda=5.8884 \times 10^{-5} \text {, }
$$

which is exact to within $\frac{1}{30} \%$, and is very near that of Angstrom (5.8889).-Comptes Rendus, June 2, 1885.

* Cornu, Annales de l'Ecole Normale supérieure, vol. ix. p. 42 (1880).

† Journal de Physique, 2nd series, vol. exi. p. 252 (1884).

$\neq$ It has been assumed that $\theta=20^{\circ}$. As this temperature is scarcely known to within $4^{\circ}$ or $5^{\circ}$, there is an uncertainty of about $\frac{1}{250} \overline{0} \overline{0}$. 